DOI 10. 18307/2017. 0510

(C) 2017 by Journal of Lake Sciences

\title{
云南阳宗海沉积物重金属污染时空特征及潜在生态风险”
}

\author{
蔡艳洁 ${ }^{1,2}$, 张恩楼 $^{2}$, 刘恩峰 $^{2}$, 袁和忠 $^{3}$, 王 荣 $^{2}$, 孔德平 $^{4}$, 周起超 ${ }^{2,4}$ \\ (1: 南京大学环境学院,南京 210023) \\ (2: 中国科学院南京地理与湖泊研究所湖泊与环境国家重点实验室, 南京 210008) \\ ( 3 : 南京信息工程大学环境科学与工程学院,南京 210044) \\ (4:云南省环境科学研究院高原湖泊流域污染过程与管理云南省重点实验室,昆明 650034)
}

\begin{abstract}
摘 要: 分析了阳宗海柱状及表层沉积物中 $\mathrm{Al} 、 \mathrm{Fe} 、 \mathrm{Mn} 、 \mathrm{Zn} 、 \mathrm{Cr} 、 \mathrm{Co} 、 \mathrm{Ni} 、 \mathrm{Cu} 、 \mathrm{As} 、 \mathrm{Cd} 、 \mathrm{~Pb}$ 等金属元素的含量,结合沉积年代 学, 研究了沉积物重金属污染的时空变化和潜在生态风险特征. 结果表明,表层沉积物中重金属含量具有一定的空间差 异性, $\mathrm{As} 、 \mathrm{Cd} 、 \mathrm{Cu} 、 \mathrm{~Pb}$ 和 $\mathrm{Zn}$ 在中东部湖区含量较高, 而 $\mathrm{Cr} 、 \mathrm{Co} 、 \mathrm{Ni}$ 含量高值位于南、北湖区的近岸区域; 柱状沉积物中, $1990 \mathrm{~s}$ 之前 $\mathrm{As} 、 \mathrm{Cd} 、 \mathrm{Cu} 、 \mathrm{~Pb}$ 和 $\mathrm{Zn}$ 含量较为稳定, 1990s 中后期以来, 其含量逐渐增加, 并在 2009-2010 年前后达到最大值, 此后逐渐下降; 而柱状沉积物中 $\mathrm{Cr} 、 \mathrm{Co} 、 \mathrm{Ni}$ 含量变化趋势与 $\mathrm{Al} 、 \mathrm{Fe}$ 相似, 总体上由下向上逐渐降低, 这主要与沉积物质地 (粒度) 逐渐变粗有关. 重金属富集系数表明, 阳宗海沉积物中主要污染元素为 $\mathrm{As} 、 \mathrm{Cd} 、 \mathrm{Cu} 、 \mathrm{~Pb}$ 和 Zn, 1990s 中后期污染程 度快速增加, 2009-2010 年前后达到峰值,此后污染程度逐渐降低; 表层沉积物中 $\mathrm{Cu}$ 为未污染至 “弱” 污染水平; $\mathrm{Zn} 、 \mathrm{~Pb}$ 为“弱一中等” 污染水平, $\mathrm{As}$ 为 “中等一强”污染水平, $\mathrm{Cd}$ 为 “弱一强”污染水平, 中东部湖区污染程度高于其他湖区, 这可能 与该湖区缺少人湖径流、自然碎屑物质沉积速率较低以及砷污染事件等人为源的重金属贡献影响更为显著有关. 生态风 险评价结果表明, 在 2002-2010 年前后沉积物重金属达到 “中等一强” 潜在生态危害, 主要贡献因子是 $\mathrm{Cd}$ 和 As, 近年来 其生态风险等级逐渐降低; 表层沉积物中重金属在中东部湖区具有 “中等” 程度潜在生态危害, 而其他湖区表层沉积物重 金属具有较低程度的潜在生态风险.
\end{abstract}

关键词: 阳宗海;沉积物;重金属;污染;潜在生态风险;时空特征

\section{Spatio-temporal characteristics of heavy metal pollution and potential ecological risk in the sediments of Lake Yangzonghai, Yunnan Province}

CAI Yanjie ${ }^{1,2}$, ZHANG Enlou ${ }^{2}$, LIU Enfeng ${ }^{2}$, YUAN Hezhong ${ }^{3}$, WANG Rong ${ }^{2}$, KONG Deping $^{4}$ \& ZHOU Qichao ${ }^{2,4}$

(1: School of the Environment, Nanjing University, Nanjing 210023, P.R.China)

(2: State Key Laboratory of Lake Science and Environment, Nanjing Institute of Geography and Limnology, Chinese Academy of Sciences, Nanjing 210008, P.R.China)

(3: School of Environmental Science and Engineering, Nanjing University of Information Science \& Technology, Nanjing 210044, P.R. China)

(4: Yunnan Key Laboratory of Pollution Process and Management of Plateau Lake-watershed, Yunnan Institute of Environmental Science, Kunming 650034, P.R.China)

Abstract: Contents of $\mathrm{Al}, \mathrm{Fe}, \mathrm{Mn}, \mathrm{Zn}, \mathrm{Cr}$, Co, Ni, Cu, As, Cd and $\mathrm{Pb}$ in the surface and core sediments of Lake Yangzonghai were determined. Combined with geochronology, the heavy metal spatio-temporal characteristics, the status relative to the pre-industrial levels, and potential ecological risk of the pollution were evaluated by the surface and core sediments from Lake Yangzonghai. The results showed that metal contents exhibited obviously spatial variations in the surface sediments. Contents of As, Cd, Cu, $\mathrm{Pb}$ and $\mathrm{Zn}$ were generally higher in the middle-east lake area than those in other areas. In contrast, contents of Cr, Co and $\mathrm{Ni}$

* 科技基础性工作专项 (2014FY110400)、国家自然科学基金项目 (41572337，41271214) 和云南省科技计划项目 (2015RA084) 联合资助. 2016-07-18 收稿; 2016-11-29 收修改稿. 蔡绝洁(1985 ), 女, 工程师; E-mail: yjcai@ niglas.ac.cn. 
showed higher values in the south lake area. Contents of $\mathrm{As}, \mathrm{Cd}, \mathrm{Cu}, \mathrm{Pb}$ and $\mathrm{Zn}$ in the core sediment had increased gradually since the mid-1990s and reached the maximum values around the year of 2009-2010, followed by a gradual decline in recent years. Contents of $\mathrm{Cr}$, Co and $\mathrm{Ni}$ showed similar temporal variations to the trends of detrital metals ( such as $\mathrm{Al}$ and $\mathrm{Fe}$ ), and they decreased generally in recent hundred years. $\mathrm{As}, \mathrm{Cd}, \mathrm{Cu}, \mathrm{Pb}$ and $\mathrm{Zn}$ in sediments of Lake Yangzonghai were contaminated as indicated by the enrichment coefficients, showing that metal contaminations began at the mid-1990s and reached the maximum values around the year of 2009-2010, but it declined gradually in recent years with the implementation of industrial discharge control. In the surface sediments, $\mathrm{Cu}$ was at unpolluted to minimal contamination levels, while $\mathrm{Zn}$ and $\mathrm{Pb}$ displayed minimal to moderate contamination levels. Metal As had moderate to strong contamination levels, and Cd showed minimal to strong contamination levels. The pollution levels of the metals in the eastern lake were higher than those in other lake areas, these are because of a relatively rare runoff, low deposition of detrital materials and high anthropogenic/detrital metal sedimentation. The metals in sediment of Lake Yangzonghai may pose a medium to strong potential ecological risk when compared with a historical pollution peak around 20022010. The main contribution factors were Cd and As. Potential eco-risks of the metals decreased in recent years and reduced to the low level except in the east lake area, where the metals may be of a moderate potential ecological risk.

Keywords: Lake Yangzonghai; sediment; heavy metals; pollution; potential ecological risk ; spatio-temporal characteristics

沉积物是水生生态系统的重要组成部分,也是重金属等污染物的重要汇 ${ }^{[1]}$. 进人水体的重金属绝大部 分被悬浮颗粒物吸附, 逐步沉降到底泥中 ${ }^{[2-3]}$; 当沉积物一水界面环境发生变化时, 沉积物中的部分重金属会 释放出来重新进人水体, 造成二次污染 ${ }^{[4]}$. 水体与沉积物中的重金属具有不可降解和生物富集两大特 征 ${ }^{[5-7]}$, 对水生生物甚至可通过食物链对人体健康产生不利影响 ${ }^{[8]}$. 研究沉积物中重金属的含量与时空变 化, 对于了解湖泊污染现状与历史过程 ${ }^{[9]}$ 、评价人类活动对湖泊环境质量的影响、湖泊生态安全保障都有非 常重要的意义 ${ }^{[10-12]}$.

阳宗海位于昆明市东南, 是云南省九大高原湖泊之一, 是环湖地区及下游重要水源, 并且具有工农业用 水的功能 ${ }^{[13]}$, 对区域经济发展起着重要的作用. 2008 年阳宗海发生了严重的砷污染事件,使得阳宗海水环 境质量下降,鱼、虾等水产品中砷的含量处于较高水平 ${ }^{[14]}$, 阳宗海砷污染受到广泛关注. 已有学者对阳宗海 水体中砷的浓度、形态分布特征开展了大量研究. 结果表明, 2008 年前后, 湖水中砷浓度经历了先升后降再 到平稳的变化过程, 2010 年后稳定在 $0.05 \mathrm{mg} / \mathrm{L}$ 左右 ${ }^{[13-16]}$. 在沉积物重金属研究方面, 张玉玺等 ${ }^{[17]}$ 对沉积物 中 $\mathrm{As} 、 \mathrm{Cu} 、 \mathrm{Cr}$ 等重金属污染特征、来源与潜在生态风险进行了研究, 但由于样品采集采用抓斗式采泥器 (采 样厚度为 $0 \sim 5 \mathrm{~cm}$ ), 无法获取 2008 年砷污染事件前后及历史时期重金属污染变化的信息; 同时研究中采用 云南省土壤作为背景, 由于不同地区土壤母质成分的差异, 可能影响重金属污染定量评价结果的准确性 ${ }^{[18]}$. 虽然部分学者以历史沉积物作为背景, 研究了阳宗海沉积物砷的污染特征 ${ }^{[17]}$, 按平均沉积速率为 $1.55 \mathrm{~mm} / \mathrm{a}^{[17]}$, 每个样品分辨率为 13 年, 在砷污染历史变化过程方面仍有一定的不足. 总之, 目前已有研究 主要侧重于阳宗海表层沉积物砷污染, 受到背景值选取与样品分辨率的局限性等因素的影响, 对于沉积物 不同重金属污染历史过程、2008 年砷污染事件后采用絮凝剂吸附沉淀除砷对沉积物重金属累积变化的影 响、以及污染定量化方面还存在一定不足.

本文通过对阳宗海柱状及表层沉积物中重金属 ( As、Cd、Co、Cr、Cu、Ni、Pb、Zn) 含量的分析, 结合沉积年 代学, 利用富集系数法和 Håkanson 潜在生态风险评价法, 并参考沉积物质量基准, 对沉积物中重金属的污染 及其潜在生态风险现状与历史变化过程进行了研究, 探讨了 2008 年砷污染排放事件对沉积物重金属富集 的影响, 以期为阳宗海环境保护提供参考.

\section{1 材料与方法}

\section{1 研究区域介绍}

阳宗海 ( $24^{\circ} 51^{\prime} \sim 24^{\circ} 58^{\prime} \mathrm{N}, 102^{\circ} 59^{\prime} \sim 103^{\circ} 02^{\prime} \mathrm{E}$ ) 属于珠江流域南盘江水系, 湖面呈纺锤形, 南北向伸展, 长 $12.7 \mathrm{~km}$, 宽 $2.5 \mathrm{~km}^{[11]}$; 高水位 $\left(1769.9 \mathrm{~m}\right.$ ) 时水面面积 $31.6 \mathrm{~km}^{2}$, 蓄水量为 $6.17 \times 10^{8} \mathrm{~m}^{3}$, 最大水深 $30 \mathrm{~m}$, 平 均水深 $20 \mathrm{~m}^{[19]}$. 流域经济以工业、农业和旅游业为主. 治金、火力发电在工业中占主导地位 ${ }^{[15]}$, 流域北部分 布有火电厂、煤矿, 三十亩南的铝厂, 南部谈葛营附近分布有磷肥厂等 ${ }^{[17]}$. 阳宗海水源补给主要来自湖面降 
雨、阳宗大河和七星河汇水、摆衣河人工补水及地下水. 汤池渠是唯一的出水口, 河水最终汇人南盘江 ${ }^{[11]}$.

\section{2 样品采集与处理}

2014 年 10 月利用 UWITEC 重力采样器在阳宗海中心 湖区采集了长 $40 \mathrm{~cm}$ 的柱状沉积物; 同时在不同湖区采集了 12 个表层 $(0 \sim 1 \mathrm{~cm})$ 沉积物样品. 采样点采用全球定位系统 (GPS) 定位,分布如图 1 所示. 柱状沉积物顶部 $0 \sim 1 \mathrm{~cm}$ 按 $0.5 \mathrm{~cm}$ 间隔分样, $1 \mathrm{~cm}$ 以下按 $1 \mathrm{~cm}$ 间隔分样, 所有样品均 置于聚乙烯塑料袋中. 样品冷冻干燥后用玛瑙研钵研磨, 过 200 目篮以备分析.

\section{3 指标分析}

1.3.1 金属元素分析 沉积物采用 $\mathrm{HCl}-\mathrm{HNO}_{3}-\mathrm{HF}^{-} \mathrm{HClO}_{4}$ 四酸 消解后用于金属元素含量分析,即取 $0.125 \mathrm{~g}$ 研磨后的干样 于聚四氟乙烯管中, 加人 $\mathrm{HCl}-\mathrm{HNO}_{3}-\mathrm{HF}-\mathrm{HClO}_{4}$, 经自动消解 仪消解, 待消解液冷却到室温后定容至 $50 \mathrm{ml}$, 混匀后即为 待测消解液. 元素 $\mathrm{Al} 、 \mathrm{Fe} 、 \mathrm{Mn}$ 和 $\mathrm{Zn}$ 用电感耦合等离子体光 谱仪 (ICP-AES, Leeman Labs Profile, USA) 测定. 将消解液再 次稀释 3 倍后利用电感耦合等离子体质谱仪 (ICP-MS, Agilent 7700x , USA ) 测定金属元素 $\mathrm{Cr} 、 \mathrm{Co} 、 \mathrm{Ni} 、 \mathrm{Cu} 、 \mathrm{As} 、 \mathrm{Cd}$ 和 $\mathrm{Pb}$ 含量. 分析过程中采用中国地质科学院地球物理地球化 学勘察研究所提供的沉积物标准物质 GSD-9 和 GSD-11 进 行精度控制, 测量误差均小于 10\%. 分析过程中所用的试剂 均为优级纯, 所用水均为超纯水.

1.3.2 年代测试 柱状沉积物中 ${ }^{210} \mathrm{~Pb}_{\mathrm{tot}}{ }^{226} \mathrm{Ra}$ 和 ${ }^{137} \mathrm{Cs}$ 的活度 采用美国 EG \& G Ortec 公司生产的高纯锗井形探测器 (HPGe GWL-120-15) 测定, 依据 Appleby ${ }^{[20]}$ 的计算方法获 得 ${ }^{210} \mathrm{~Pb}_{\mathrm{ex}}$ 活度. ${ }^{137} \mathrm{Cs}$ 和 ${ }^{226} \mathrm{Ra}$ 的标准样品由中国原子能科学

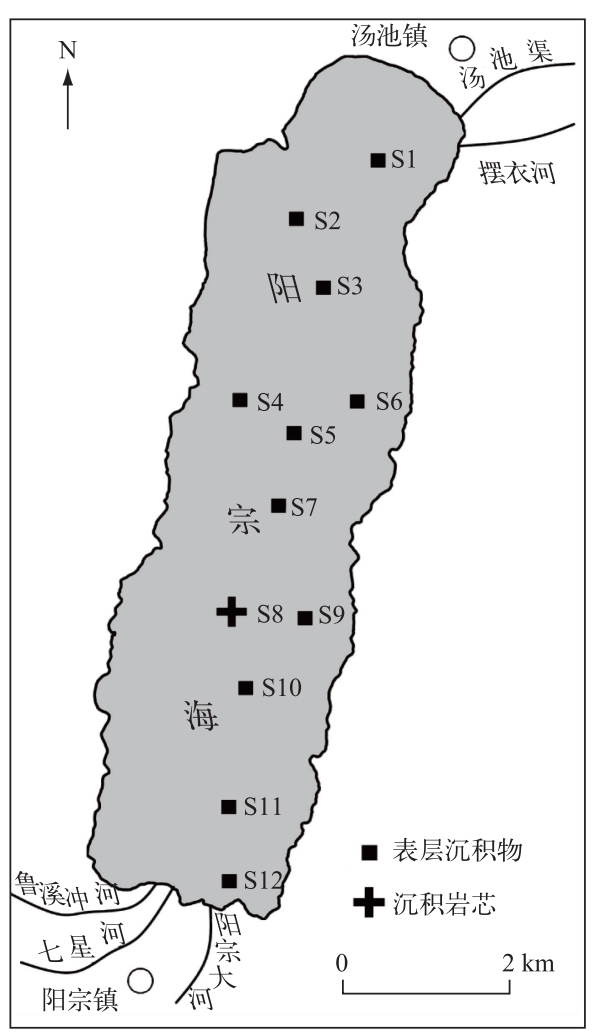

图 1 阳宗海采样点位置

Fig. 1 Sampling sites of Lake Yangzonghai 研究院提供, ${ }^{210} \mathrm{~Pb}$ 标准样品由英国利物浦大学做比对标准,计数误差小于 $10 \%$.

\section{4 重金属污染与生态风险评价方法}

1.4.1 重金属污染评价 目前, 国内外学者常用且具有代表性的沉积物中重金属污染评价方法有富集系数法 (Enrichment Factor, $E F$ )、地积累指数法 ${ }^{[21-22]}$ 等, 其中, 富集系数法可以有效校正沉积物粒度和矿物组成变化 对重金属含量的影响 ${ }^{[23]}$, 在重金属污染定量化方面具有更高的可靠性. 富集系数 $E F$ 的计算公式为 ${ }^{[24]}$ :

$$
E F=(M / X)_{\text {样品 }} /(M / X)_{\text {背景 }}
$$

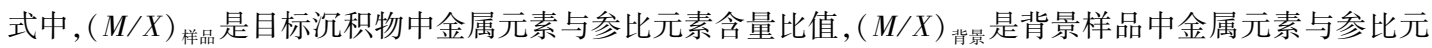
素含量比值. 沉积物中 $\mathrm{Al} 、 \mathrm{Fe}$ 等常量金属元素以流域自然来源为主 ${ }^{[25]}$, 其含量指示了流域物源区土壤与岩 石碎屑成分供给的变化,可作为参比元素用于沉积物与重金属含量自然变化的矫正 ${ }^{[26]}$. 为降低单一元素矫 正的误差,本文选取 $\mathrm{Al}$ 和 $\mathrm{Fe}$ 分别作为参比元素计算得到各重金属元素的 $E F$ 平均值 ${ }^{[24]}$.

沉积物背景值的选取直接影响到重金属富集系数和综合潜在生态风险指数的计算结果, 许多研究者使 用区域土壤或地壳中金属元素平均值来作为背景值 ${ }^{[11,15]}$. 研究表明, 对湖泊等面积较小的水体单元进行沉 积物重金属污染评价时,采用上述背景值时往往由于区域母质成分的显著差异, 导致评价结果产生较大误 差 ${ }^{[18,24]}$. 为更好地反映湖泊沉积物重金属污染程度, 采用历史沉积物作为背景值进行沉积物重金属污染评 价更为合适 ${ }^{[27-28]}$. 根据柱状沉积物测年结果, 本文采用柱状沉积物底部样品 (工业革命前) 中金属元素含量 作为背景值 (表 1 ).

1.4.2 潜在生态风险评价 潜在生态风险指数法和沉积物质量基准法是沉积物重金属生态风险评价常用的 方法. 潜在生态风险指数法由瑞典学者 Håkanson 于 1980 年提出 ${ }^{[29]}$, 该方法同时考虑了沉积物中金属含量、 
污染物的种类与毒性水平 3 个因素 ${ }^{[30]}$, 不仅可以反映沉积物中单一重金属污染的环境影响, 也可以体现多 种重金属污染物的综合生态危害 ${ }^{[31]}$. 重金属综合潜在生态风险指数 $(R I)$ 的计算公式为:

$$
R I=\sum E_{r}^{i}=\sum T_{r}^{i} \cdot C_{s}^{i} / C_{n}^{i}
$$

式中, $E_{r}^{i}$ 为重金属 $i$ 的潜在生态风险系数, $C_{s}^{i}$ 为沉积物中重金属 $i$ 的实测含量, $C_{n}^{i}$ 为重金属 $i$ 的背景值, $T_{r}^{i}$ 为 重金属 $i$ 的毒性响应因子 (表 1). 重金属单因子生态风险参数 $(E r)$ 与 $R I$ 的分级标准见表 2 .

沉积物质量基准是沉积物环境质量的综合评判标准, 可以反映沉积物中重金属对水体生物的潜在毒 性 ${ }^{[32-33]}$. 目前全球沉积物质量基准有 10 多种, 不同质量基准中重金属含量阈值存在一定差异 ${ }^{[32]}$. 本文采用 MacDonald 等 ${ }^{[34]}$ 建立的淡水水体沉积物重金属质量基准( Consensus-Based SQGs, CBSQGs), 包括阈值效应含 量 $(T E C)$ 与可能效应含量 $(P E C)$ ( 表 1). 若沉积物金属含量低于 $T E C$ 时, 有害生物效应发生的可能性较小; 若沉积物金属含量高于 $P E C$ 时, 有害生物效应发生的可能性较大; 若金属含量介于 $T E C$ 和 $P E C$ 之间, 则有 害生物效应可能发生 ${ }^{[32,34]}$.

表 1 金属背景值、毒性响应系数及沉积物质量基准值*

Tab.1 Background values and toxic response coefficient of metals and the consensus-based sediment quality guidelines

\begin{tabular}{ccccccccccc}
\hline & $\mathrm{Al}$ & $\mathrm{Fe}$ & $\mathrm{Cr}$ & $\mathrm{Co}$ & $\mathrm{Ni}$ & $\mathrm{Zn}$ & $\mathrm{Cu}$ & $\mathrm{As}$ & $\mathrm{Cd}$ & $\mathrm{Pb}$ \\
\hline 背景值 & 104 & 63.6 & 169 & 28.1 & 67.7 & 110 & 94.6 & 26.6 & 0.66 & 39.8 \\
毒性响应系数 & - & - & 2 & 5 & 5 & 1 & 5 & 10 & 30 & 5 \\
阈值效应含量 & - & - & 43.4 & - & 22.7 & 121 & 31.6 & 9.79 & 0.99 & 35.8 \\
可能效应含量 & - & - & 111 & - & 48.6 & 459 & 149 & 33 & 4.98 & 128 \\
\hline
\end{tabular}

$* \mathrm{Al} 、 \mathrm{Fe}$ 含量单位为 $\mathrm{g} / \mathrm{kg} ; \mathrm{Zn} 、 \mathrm{Cr} 、 \mathrm{Co} 、 \mathrm{Ni} 、 \mathrm{Cu} 、 \mathrm{As} 、 \mathrm{Cd} 、 \mathrm{~Pb}$ 含量单位为 $\mathrm{mg} / \mathrm{kg}$.

表 2 单因子生态风险系数与综合潜在生态风险指数的分级标准

Tab.2 Classification of the potential ecological risk factor $(E r)$ and the potential ecological risk index $(R I)$

\begin{tabular}{|c|c|c|c|}
\hline 单因子污染物潜在生态风险系数 & 单因子污染物生态风险等级 & 综合潜在生态风险指数 & 综合潜在生态风险等级 \\
\hline$E r<40$ & 轻微 & $R I<150$ & 低微 \\
\hline $40 \leqslant E r<80$ & 中等 & $150 \leqslant R I<300$ & 中等 \\
\hline $80 \leqslant E r<160$ & 强 & $300 \leqslant R I<600$ & 强 \\
\hline $160 \leqslant E r<320$ & 很强 & $R I \geqslant 600$ & 严重 \\
\hline$E r \geqslant 320$ & 极强 & & \\
\hline
\end{tabular}

\section{2 结果与讨论}

\section{1 沉积岩芯年代}

柱状沉积物中 ${ }^{210} \mathrm{~Pb}_{\text {ex }}$ 随深度增加总体呈指数降低 $\left(R^{2}=0.81\right)$, 柱状沉积物 $14.5 \mathrm{~cm}$ 处 ${ }^{137} \mathrm{Cs}$ 出现显著的 峰值, 对应于 1963 年全球核爆试验大气沉降蓄积峰值 ${ }^{[20]}$. 柱状沉积物中 ${ }^{137} \mathrm{Cs}$ 和 ${ }^{210} \mathrm{~Pb}$ 的变化特征指示了较 为稳定的沉积序列, 采用复合模式建立柱状沉积物的年代 ${ }^{[20,35]}$, 年代结果见文献 $[36]$.

\section{2 沉积物中重金属的含量与分布}

阳宗海柱状及表层沉积物中各金属元素含量均表现出一定的变化, 柱状沉积物金属元素含量变异系数 大于表层沉积物. 柱状沉积物与表层沉积物中 $\mathrm{Cd}$ 含量的变异系数最大, 最高含量分别为最低含量的 14.5 和 4.2 倍; $\mathrm{Ni}$ 含量的变异系数最小, 其含量最大值分别为最小值的 2.5 和 1.6 倍 (表 3 ).

对柱状沉积物的金属元素进行 $\mathrm{R}$ 型聚类分析,金属元素变化可分为两组,第 I 组元素包括 $\mathrm{Al} 、 \mathrm{Fe} 、 \mathrm{Cr} 、 \mathrm{Co}$ 和 $\mathrm{Ni}$, 其含量总体呈由下向上逐渐降低的趋势, 特别是在柱状沉积物上部表现得较为明显. 第 II 组元素包括 $\mathrm{As} 、 \mathrm{Cd} 、 \mathrm{Cu} 、 \mathrm{~Pb}$ 和 Zn, 其含量呈现三段式变化规律: 第一阶段, 柱状沉积物下部 (40 8 cm), 即在 1998 年之 前, 金属元素含量较低且变化趋势不明显; 第二阶段, 在柱状沉积物中部 $(8 \sim 3 \mathrm{~cm})$, 即 $1998-2010$ 年之间, 
金属元素含量急剧增加; 第三阶段, 在柱状沉积物上部 ( $3 \sim 0 \mathrm{~cm}$ ), 即 2010 年之后, 金属元素含量逐渐减小 (图 2、图 3). 第 I 组元素含量垂向波动程度较小, 变异系数均小于 0.5 ; 第 II 组元素中 $\mathrm{Cd}$ 和 $\mathrm{As}$ 具有较大的 变异性,其变异系数分别为 1.27 和 1.10 ; 其次是 $\mathrm{Zn}$ 和 $\mathrm{Pb}$,变异系数分别为 0.73 和 0.51 (表 3 ).

表层沉积物金属元素 $\mathrm{R}$ 型聚类结果与柱状沉积物类似, 也可分为两组 (图 2) : $\mathrm{As} 、 \mathrm{Cd} 、 \mathrm{Cu} 、 \mathrm{~Pb}$ 和 $\mathrm{Zn}$ 含量 的空间变化相似, 最高值都位于中东部湖区 (采样点 S9) ; $\mathrm{Cr} 、 \mathrm{Co}$ 和 $\mathrm{Ni}$ 含量最高值都位于南部与北部湖区的 近岸区域 (图 4). 表层沉积物中各金属元素的变异系数相对较小, 除了 As 平均含量高于柱状沉积物均值之 外, 表层沉积物中其余金属元素含量均低于柱状沉积物中金属元素平均含量.

沉积物中 $\mathrm{Al} 、 \mathrm{Fe}$ 等硅酸盐类元素以流域自然来源为主, 阳宗海柱状与表层沉积物中 $\mathrm{Cr} 、 \mathrm{Co} 、 \mathrm{Ni}$ 与 $\mathrm{Al} 、 \mathrm{Fe}$ 呈现相似的变化规律, 其含量变化可能是受到了沉积物质地 (粒度) 变化的影响 ${ }^{[24]}$; 而 $\mathrm{As} 、 \mathrm{Cd} 、 \mathrm{Cu} 、 \mathrm{~Pb} 、 \mathrm{Zn}$ 与 $\mathrm{Al} 、 \mathrm{Fe}$ 呈现不同的组合特征,其含量除了自然来源之外, 还可能受到人为活动的影响.

表 3 阳宗海沉积物金属元素含量及变异系数*

Tab.3 Descriptive statistics of the metal contents in sediments of Lake Yangzonghai and the coefficient of variation

\begin{tabular}{|c|c|c|c|c|c|c|c|c|c|c|c|c|}
\hline & & $\mathrm{Al}$ & $\mathrm{Fe}$ & Mn & $\mathrm{Cr}$ & Co & $\mathrm{Ni}$ & $\mathrm{Zn}$ & $\mathrm{Cu}$ & As & $\mathrm{Cd}$ & $\mathrm{Pb}$ \\
\hline \multirow[t]{4}{*}{ 柱状沉积物 } & 最大值 & 106 & 64.8 & 677 & 180 & 28.9 & 71.2 & 534 & 180 & 253 & 7.95 & 142 \\
\hline & 最小值 & 35.5 & 27.5 & 390 & 48.7 & 10.0 & 28.4 & 88.4 & 58.2 & 20.5 & 0.55 & 35.0 \\
\hline & 均值 & 77.8 & 49.1 & 550 & 119 & 20.7 & 49.8 & 143 & 92.3 & 58.5 & 1.63 & 48.4 \\
\hline & 变异系数 & 0.28 & 0.24 & 0.12 & 0.32 & 0.27 & 0.26 & 0.73 & 0.28 & 1.10 & 1.27 & 0.51 \\
\hline \multirow[t]{4}{*}{ 表层沉积物 } & 最大值 & 75.2 & 53.2 & 567 & 84.7 & 16.9 & 45.0 & 247 & 90.6 & 158 & 3.01 & 63.6 \\
\hline & 最小值 & 34.7 & 23.0 & 305 & 43.5 & 8.20 & 28.4 & 79.9 & 38.1 & 81.5 & 0.72 & 25.9 \\
\hline & 均值 & 45.4 & 31.8 & 423 & 56.2 & 12.0 & 32.8 & 136 & 60.7 & 110 & 1.47 & 40.0 \\
\hline & 变异系数 & 0.25 & 0.25 & 0.20 & 0.20 & 0.19 & 0.15 & 0.32 & 0.23 & 0.21 & 0.45 & 0.25 \\
\hline
\end{tabular}

$* \mathrm{Al} 、 \mathrm{Fe}$ 含量单位为 $\mathrm{mg} / \mathrm{g} ; \mathrm{Cr} 、 \mathrm{Co} 、 \mathrm{Ni} 、 \mathrm{Zn} 、 \mathrm{Cu} 、 \mathrm{As} 、 \mathrm{Cd} 、 \mathrm{~Pb}$ 含量单位为 $\mathrm{mg} / \mathrm{kg}$.

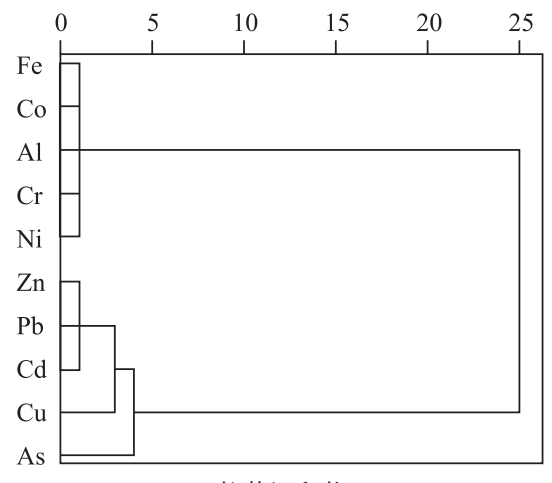

柱状沉积物

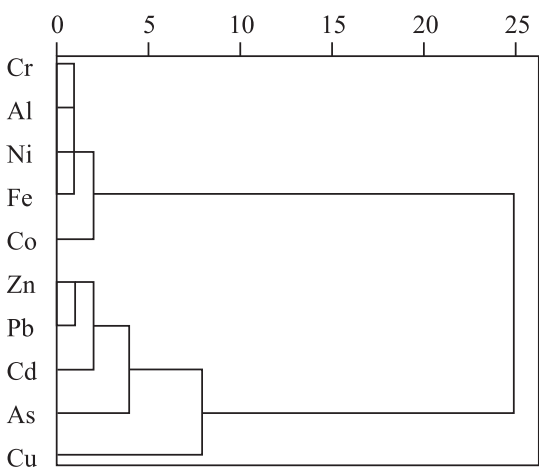

表层沉积物

图 2 阳宗海柱状及表层沉积物金属元素 $\mathrm{R}$ 型聚类分析结果

Fig. 2 Hierarchical analysis of metals in the core and surface sediments from Lake Yangzonghai

\section{3 沉积物中重金属污染水平及来源分析}

柱状沉积物中 $\mathrm{Cr} 、 \mathrm{Co} 、 \mathrm{Ni}$ 的富集系数变化较为稳定, 为 $0.7 \sim 1.1$ (图 5). $\mathrm{As} 、 \mathrm{Cd} 、 \mathrm{Cu} 、 \mathrm{~Pb}$ 和 $\mathrm{Zn}$ 的富集系数 变化较大, 其中 1998 年之前较为稳定, 为 $0.8 \sim 1.1 ; 1998-2010$ 年其富集系数明显增加, 分别达到了 $1.1 \sim$ $24.9 、 1.2 \sim 31.5 、 1.2 \sim 5.0 、 1.1 \sim 9.3 、 1.1 \sim 12.6 ; 2010$ 年后富集系数又明显下降(图 5). 表层沉积物中 $\mathrm{Cr} 、 \mathrm{Co} 、 \mathrm{Ni}$ 的富集系数分别为 $0.6 \sim 0.8 、 0.7 \sim 1.0 、 0.8 \sim 1.2$, 其中 $\mathrm{Ni}$ 的富集系数在采样点 $\mathrm{S} 4$ 处略高, 为 $1.2 ; \mathrm{Zn} 、 \mathrm{Cu} 、 \mathrm{As}$ 、 $\mathrm{Cd} 、 \mathrm{~Pb}$ 的富集系数分别为 1.3 4.5、1.0 1.9、3.9 12.2、1.4 9.2、1.1 3.2, 明显高于其他金属元素 (图 6). 参 考重金属富集系数与污染等级划分标准 ${ }^{[37]}$, 阳宗海柱状沉积物中 $\mathrm{Cr} 、 \mathrm{Co} 、 \mathrm{Ni}$ 为无污染水平, $\mathrm{Cu}$ 为 “弱一中 


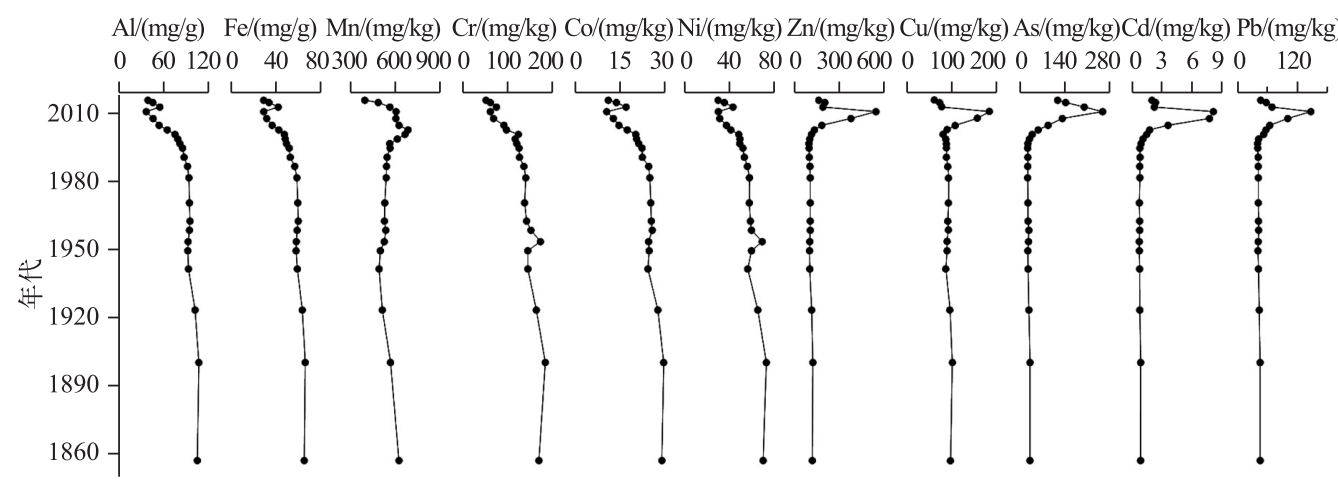

图 3 阳宗海柱状沉积物金属元素含量

Fig.3 Vertical variations of metal concentrations in the core sediment from Lake Yangzonghai
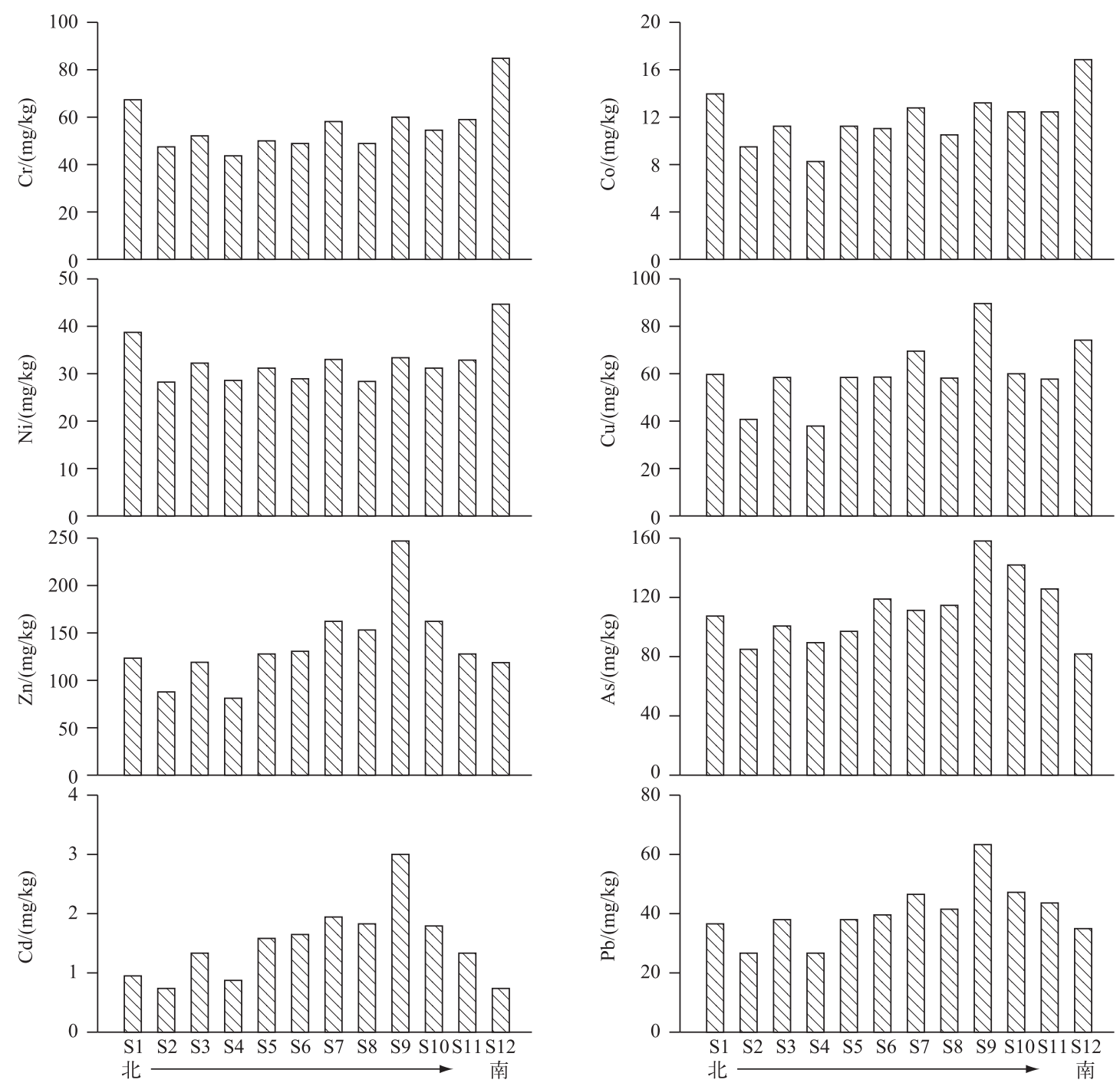

图 4 阳宗海表层沉积物金属元素含量

Fig.4 Contents of the metals in the surface sediments from Lake Yangzonghai 
等” 污染, $\mathrm{Zn} 、 \mathrm{~Pb}$ 为 “弱一强” 污染, $\mathrm{As} 、 \mathrm{Cd}$ 为 “弱一很强” 污染; 表层沉积物中 $\mathrm{Cr} 、 \mathrm{Co} 、 \mathrm{Ni} 、 \mathrm{Cu}$ 为无污染水平, 为 “弱一中等”污染, As 为“中等一强”污染, Cd 为“弱一强”污染.

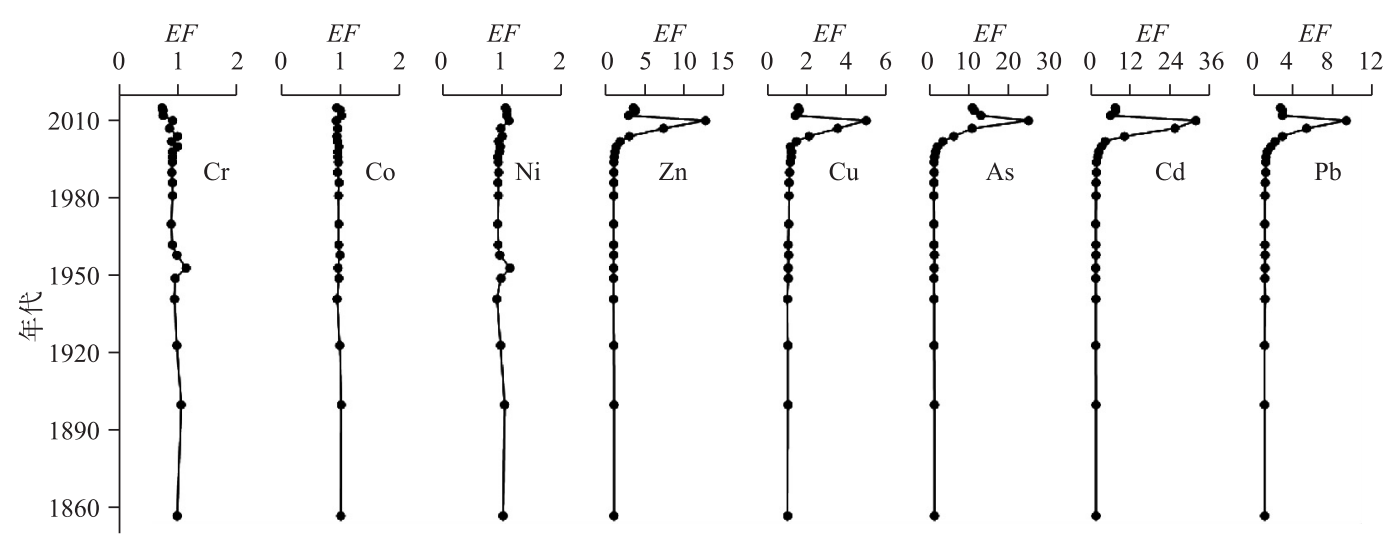

图 5 阳宗海柱状沉积物金属元素富集系数

Fig.5 Enrichment factor values of metals in the core sediment from Lake Yangzonghai

$\mathrm{Zn} 、 \mathrm{~Pb}$ 早期成岩作用是沉积物中金属元素变化的重要因素之一 ${ }^{[38]}$,已有研究表明,早期成岩作用对淡 水湖泊中沉积物重金属垂向分布的影响可达几厘米 ${ }^{[39]}$. 氧化还原作用是影响沉积物中重金属垂向迁移的 主要因素, $\mathrm{Fe} 、 \mathrm{Mn}$ 在沉积物一水界面具有较强的氧化还原敏感性, 受早期成岩作用影响易在表层沉积物中富 集,对早期成岩作用具有一定的指示意义 ${ }^{[40]}$. 阳宗海柱状沉积物顶部 Fe、Mn 并未发现明显的富集, As、Cd、 $\mathrm{Cu} 、 \mathrm{~Pb}$ 和 $\mathrm{Zn}$ 含量和富集系数的垂向变化与 $\mathrm{Fe} 、 \mathrm{Mn}$ 无明显对应关系, 说明这几种重金属元素垂向变化受早 期成岩作用影响较弱. 因此, 阳宗海柱状沉积物中重金属富集系数的变化主要反映了人为污染的变化.

阳宗海柱状沉积物中 $\mathrm{As} 、 \mathrm{Cd} 、 \mathrm{Cu} 、 \mathrm{~Pb}$ 和 $\mathrm{Zn}$ 的含量和富集系数具有相似的垂向变化规律, 其最大值均出 现于 2009-2010 年前后,此后逐渐降低, 表明 Zn、Cu、Cd、Pb 污染与 As 污染具有同源性. Zhang 等 ${ }^{[27]}$ 于 2007 年对采集的柱状沉积物研究发现, 约 2000 年以来 $\mathrm{Pb} 、 \mathrm{Zn}$ 污染逐渐加重, 这与本次研究采集的柱状沉积物中 $\mathrm{Pb} 、 \mathrm{Zn}$ 的变化规律一致, 说明在 2008 年砷污染事件之前, 阳宗海已存在重金属污染. 1998 年以来, As、Cd、Cu、 $\mathrm{Pb}$ 和 $\mathrm{Zn}$ 污染程度快速加剧, 并在 2009-2010 年左右达到峰值, 之后逐渐下降 (图 3), 这也与阳宗海流域人类 活动强度及工业发展历史较吻合 ${ }^{[41]} .1990 \mathrm{~s}$ 中后期, 随着城市快速发展的需要, 阳宗海沿岸兴建了许多工矿企 业及旅游度假村, 尤其以火电厂、煤矿业及温泉度假村等为主, 大量的工业废水不断排人阳宗海, 重金属等污 染物在沉积物中逐渐聚集, 污染程度不断上升. 2008 年发生砷污染事件后, 为了降低水体砷浓度及其生态环境 危害, 采用了絮凝剂吸附沉淀法, 使水体中的砷及其他重金属快速沉降至沉积物中,因此 2009-2010 年前后柱 状沉积物中 $\mathrm{As} 、 \mathrm{Cu} 、 \mathrm{Cd} 、 \mathrm{~Pb} 、 \mathrm{Zn}$ 等重金属含量与污染达到峰值可能与絮凝剂除砷导致的重金属元素沉淀有 关. 2008 年后,有关部门出台了一系列政策治理阳宗海流域水体污染 ${ }^{[42]}$, 这可能是沉积物中重金属污染快 速降低的主要原因. 燕婷等 ${ }^{[28]}$ 对抚仙湖的研究表明,抚仙湖的污染始于 $1980 \mathrm{~s}$ 中期; 而刘勇等 ${ }^{[43]}$ 对滇池的 研究表明,滇池沉积物重金属从 1950s 开始变化明显,近 60 年来重金属污染急剧加重,重金属污染时间点远 远早于阳宗海, 反映了云南地区不同湖泊重金属污染历史过程具有一定的差异性,这可能与流域内经济发 展历史过程不同有关.

虽然近年来阳宗海沉积物重金属污染程度快速降低,但表层沉积物中 $\mathrm{As} 、 \mathrm{Cd} 、 \mathrm{~Pb} 、 \mathrm{Zn}$ 等重金属含量仍高 于历史背景值, 污染程度为 “弱” 至 “强”, 说明目前仍有人为源重金属的输人. 人为活动释放到水体中的重 金属吸附在悬浮颗粒物中快速沉降到湖泊底泥中, 因此沉积物中重金属污染空间变化可以间接反映污染源 分布 ${ }^{[44]}$. 张玉玺等 ${ }^{[11]}$ 和王振华等 ${ }^{[14]}$ 研究表明, 工业废水排放是阳宗海沉积物重金属污染的主要来源, 阳宗 海主要重金属潜在污染源 (工业) 主要分布于其西部、北部与南部, 而东部较少 ${ }^{[17]}$. 从表层沉积物重金属富 集系数分布来看, As、Cd、Pb、Zn 等重金属元素污染程度由北部湖区向中部湖区逐渐增加 (采样点 $\mathrm{S} 1 \sim \mathrm{S} 9$ ), 而南部湖区(采样点 S10 S12) 沉积物中重金属污染程度相对较弱 (图 6), 这说明上述重金属主要污染源位 

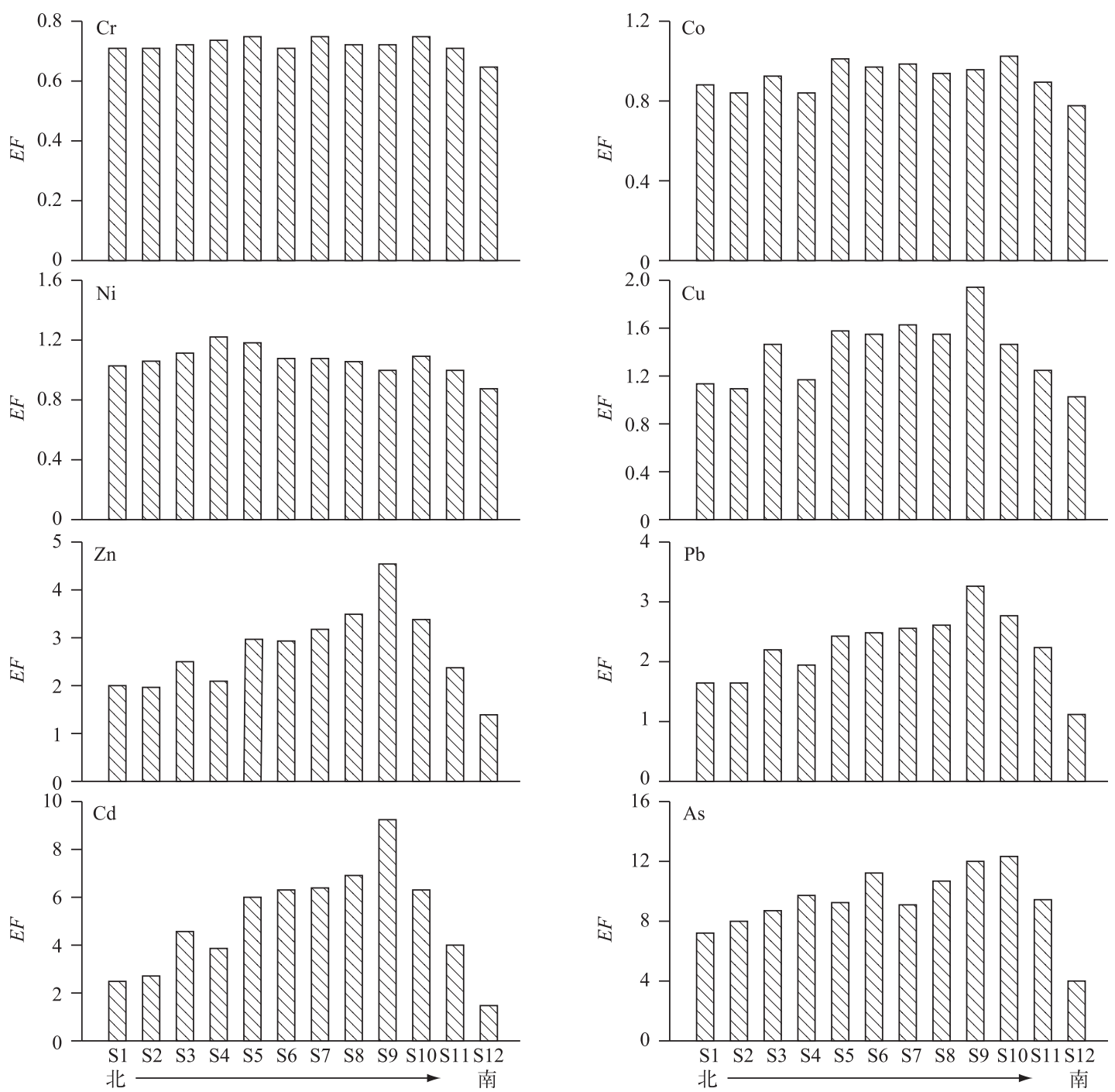

图 6 阳宗海表层沉积物金属元素富集系数

Fig.6 Enrichment factor values of metals in the surface sediments from Lake Yangzonghai

于阳宗海流域中部地区. 阳宗海中东部湖区 (采样点 S9) 沉积物中 $\mathrm{As} 、 \mathrm{Cd} 、 \mathrm{Zn} 、 \mathrm{~Pb} 、 \mathrm{Cu}$ 等重金属污染相对较 重, 这可能是由于阳宗海东岸缺少径流带来的泥沙补给, 沉积速率较慢, 自然来源颗粒物在沉积物中所占比 重较低,对沉积物中重金属的稀释作用小于其他湖区,因此中东部湖区沉积物表现为相对较重的人为污染. 由于本次研究只采集了 12 个表层样品, 在今后的研究中还需加密表层沉积物采样点分布, 进一步研究阳宗 海东部湖区 S9 采样点附近重金属含量与风险较高是区域性现象、还是与局地沉积环境有关.

云贵高原地区是我国重要的有色金属产区,已有研究表明,西南地区湖泊沉积物中 $\mathrm{Pb} 、 \mathrm{Zn}$ 等重金属普 遍受到大气沉降的影响 ${ }^{[45]}$. 因此,除了流域内人为源重金属的直接输人之外,大气沉降也可能是阳宗海表 层沉积物重金属污染的重要来源之一.

\section{4 沉积物中重金属的生态风险评价}

柱状沉积物中 $\mathrm{Cr} 、 \mathrm{Co} 、 \mathrm{Ni} 、 \mathrm{Zn} 、 \mathrm{Cu} 、 \mathrm{~Pb}$ 的生态风险系数均小于 40 , 属于 “轻微” 潜在生态风险; $\mathrm{As}$ 的潜在生 态风险系数从 1998 年开始急剧上升, 在 2009-2010 年左右达到最大值, 达 “强”潜在生态风险, 之后逐渐下 
降至 “轻微” 潜在生态风险等级; Cd 的潜在生态风险系数从 1998 年开始逐渐上升, 并在 2009-2010 年左右达 到最大值, 具有 “极强” 的潜在生态风险, 之后快速下降至 “中等”潜在生态风险等级. 各金属的生态风险依次为 $\mathrm{Cd}>\mathrm{As} \gg \mathrm{Pb} \approx \mathrm{Cu}>\mathrm{Ni} \approx \mathrm{Co} \approx \mathrm{Cr} \approx \mathrm{Zn}$. 柱状沉积物中 8 种重金属元素的 $R I$ 值范围为 53 493, 属于“低一强”潜在 生态危害, 其中 2009-2010 年前后沉积物中重金属潜在生态风险程度最高, $\mathrm{Cd}$ 和 As 对综合潜在生态危害 指数的贡献率超过 $80 \%$, 为主要生态风险因子 (图 7). 以上分析结果表明, 2009-2010 年前后沉积物中重金 属潜在生态风险经历了“低一高一低”的变化规律, 随着 2009-2010 年以来流域工业污染治理与减排措施的 实施, 阳宗海沉积物重金属潜在生态风险明显降低.

表层沉积物各采样点的重金属潜在生态风险系数和综合潜在生态风险指数的空间变化如图 8 所示. Cd 在采样点 $\mathrm{S} 7 、 \mathrm{~S} 8 、 \mathrm{~S} 9 、 \mathrm{~S} 10$ 具于 “强” 潜在生态风险, 在采样点 $\mathrm{S} 1 、 \mathrm{~S} 3 、 \mathrm{~S} 5 、 \mathrm{~S} 6 、 \mathrm{~S} 11$ 为“中等”潜在生态风险, 在其 他区域为 “轻微”潜在生态风险; As 在采样点 $\mathrm{S} 6 、 \mathrm{~S} 7 、 \mathrm{~S} 8 、 \mathrm{~S} 9 、 \mathrm{~S} 10 、 \mathrm{~S} 11$ 处于 “中等”潜在生态风险, 在其他区域 为 “轻微” 潜在生态风险; $\mathrm{Cr} 、 \mathrm{Co} 、 \mathrm{Ni} 、 \mathrm{Zn} 、 \mathrm{Cu}$ 和 $\mathrm{Pb}$ 在所有表层沉积物中的潜在生态风险等级均为 “轻微”. 综 合潜在生态风险指数结果显示, 采样点 S9 沉积物中重金属达到“中等” 以上潜在生态危害程度, 其他区域沉 积物重金属均处于“较低”潜在生态危害等级.

参考沉积物质量基准法, 阳宗海表层沉积物所有采样点中 $\mathrm{Cr} 、 \mathrm{Ni} 、 \mathrm{Cu}$ 含量均介于 $T E C$ 和 $P E C$ 值之间, 说明这几种重金属在整个湖区有可能发生生态毒性效应. Zn、Cd、Pb 含量介于 $T E C$ 和 PEC 值之间的百分比 均为 $75 \%$, 说明这几种重金属在绝大部分湖区有可能发生生态毒性效应. 而 As 含量在全湖区都高于 PEC 值, 说明 As 发生生态毒性效应的概率较高.

潜在生态风险指数法和沉积物质量基准法对 $\mathrm{Cr} 、 \mathrm{Co} 、 \mathrm{Ni} 、 \mathrm{Cu} 、 \mathrm{~Pb}$ 和 $\mathrm{Zn}$ 的评价结果具有明显的差异. 质量 基准法主要考虑了重金属的含量 ${ }^{[36]}$, 而生态风险指数法不仅考虑了重金属含量和毒性效应, 还受到重金属 背景值的影响 ${ }^{[34]}$. 有研究表明, 由于不同地区背景值差异较大,TEC-PEC 标准对 $\mathrm{Cr} 、 \mathrm{Ni}$ 的评价存在一定的局 限性 ${ }^{[17]}$. 质量基准法对 $\mathrm{Cr} 、 \mathrm{Co} 、 \mathrm{Ni} 、 \mathrm{Cu} 、 \mathrm{~Pb}$ 和 $\mathrm{Zn}$ 生态风险评价结果高于重金属单项生态风险, 可能与阳宗海 较高的重金属背景值有关. 潜在生态风险指数法和沉积物质量基准法对 $\mathrm{As}$ 和 $\mathrm{Cd}$ 的评价结果基本一致,都 指出 $\mathrm{As}$ 和 $\mathrm{Cd}$ 具有一定程度的潜在生态风险并且有可能发生生态毒性效应. 结合重金属污染程度结果, 认 为阳宗海表层沉积物中 $\mathrm{Cr} 、 \mathrm{Co} 、 \mathrm{Ni} 、 \mathrm{Cu}$ 潜在生态风险较低; $\mathrm{Zn} 、 \mathrm{~Pb}$ 虽然污染程度相对较高, 但由于其生态毒 性较低, 因而其潜在生态风险相对较低; As 和 Cd 是阳宗海沉积物重金属污染的主要贡献因子, 并且具有一 定程度的潜在生态风险.

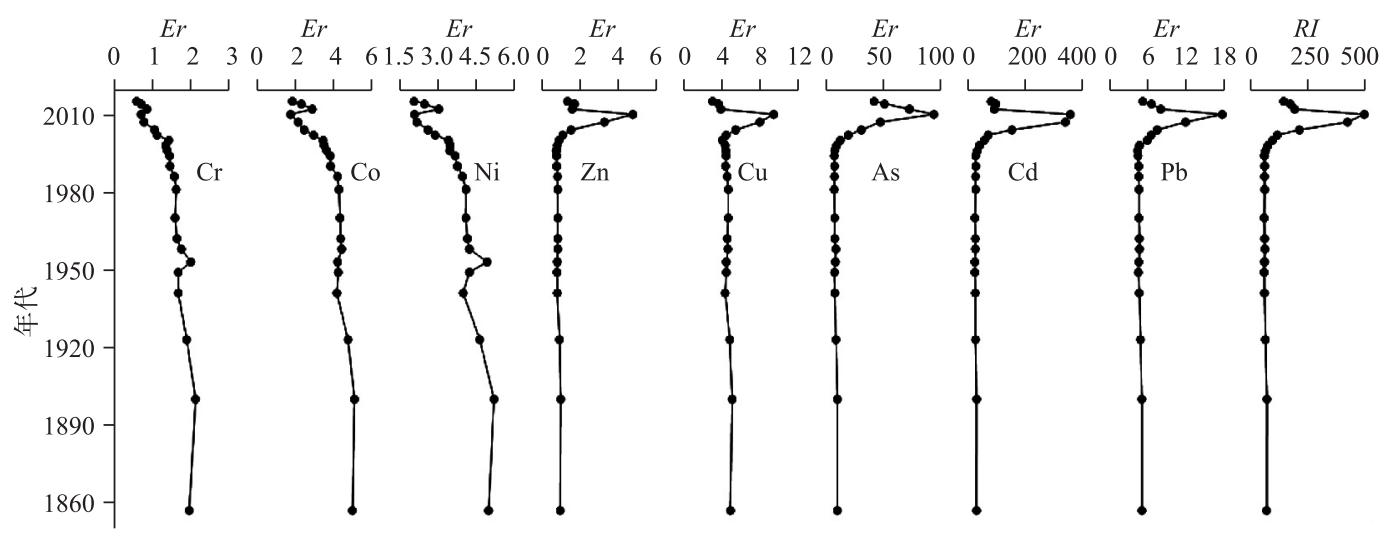

图 7 阳宗海柱状沉积物金属潜在生态风险系数及综合潜在生态风险指数

Fig.7 Vertical variations of the metal-specific potential ecological risk factor and the potential ecological risk index of metals in the core sediment from Lake Yangzonghai

\section{3 结论}

近 150 年来阳宗海柱状沉积物中金属 $(\mathrm{Cr} 、 \mathrm{Co} 、 \mathrm{Ni} 、 \mathrm{Zn} 、 \mathrm{Cu} 、 \mathrm{As} 、 \mathrm{Cd} 、 \mathrm{~Pb})$ 的垂向变化趋势存在明显差异, 受 


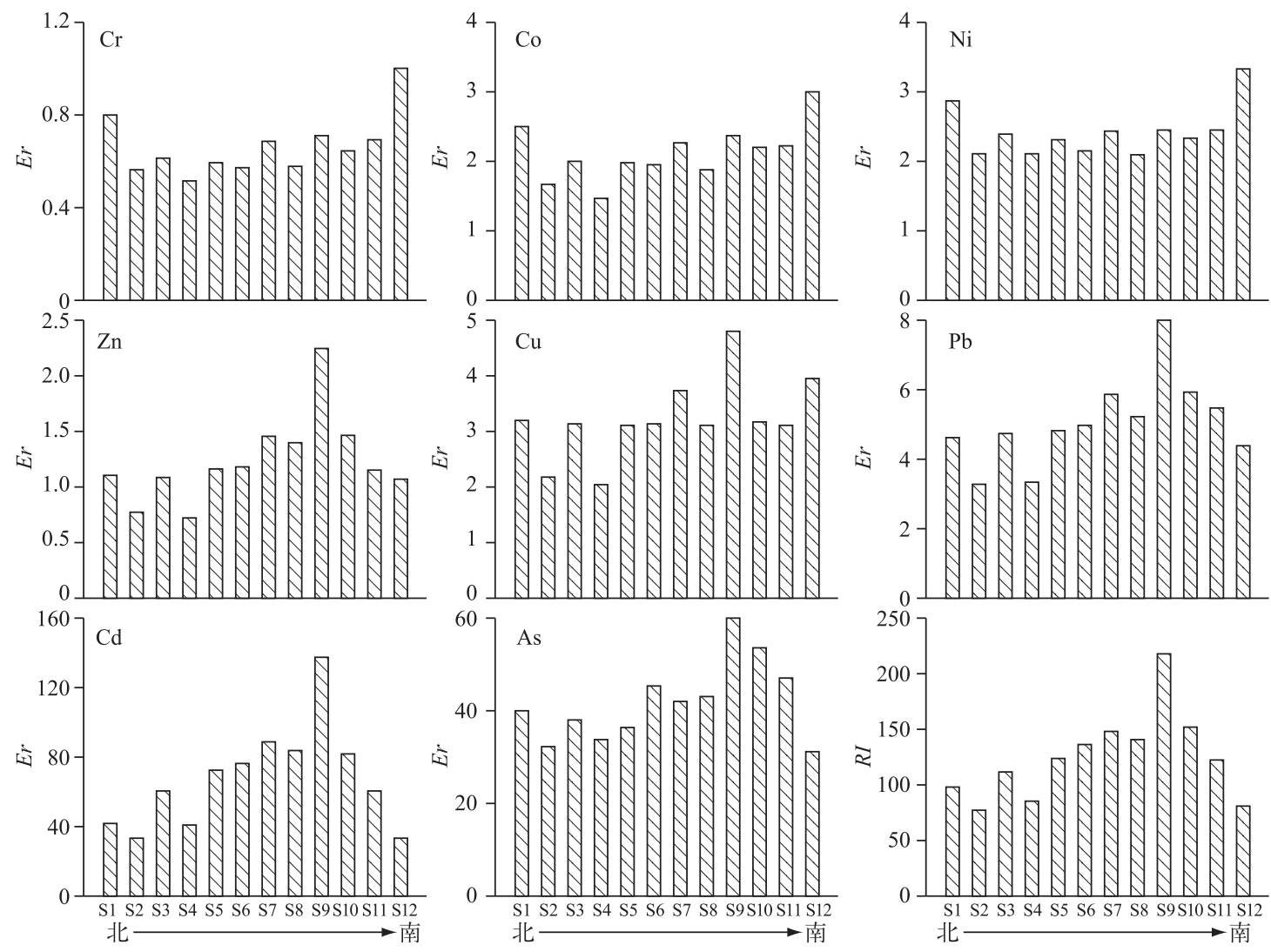

图 8 阳宗海表层沉积物金属潜在生态风险系数及综合潜在生态风险指数

Fig.8 Spatial variations of the metal-specific potential ecological risk factor and the potential ecological risk index of metals in the surface sediments from Lake Yangzonghai

沉积物质地的影响, $\mathrm{Cr} 、 \mathrm{Co} 、 \mathrm{Ni}$ 含量总体上逐渐降低, 而 $\mathrm{As} 、 \mathrm{Cu} 、 \mathrm{Cd} 、 \mathrm{~Pb} 、 \mathrm{Zn}$ 含量则表现为由稳定转向急剧增 长的趋势, 并在 2009-2010 年左右出现转折点, 之后其含量逐年下降. 表层沉积物中重金属含量的分布呈 现两种不同的组合特征: $\mathrm{Cr} 、 \mathrm{Co} 、 \mathrm{Ni}$ 分布较相似,最高值出现于阳宗海南、北湖区的近岸区域; 而 $\mathrm{As} 、 \mathrm{Cu} 、 \mathrm{Cd}$ 、 $\mathrm{Pb} 、 \mathrm{Zn}$ 的最高浓度出现在阳宗海中东部湖区.

重金属富集系数结果表明,1990s 中后期开始阳宗海沉积物重金属明显受到人为污染的影响,主要污染 元素为 $\mathrm{As} 、 \mathrm{Cu} 、 \mathrm{Cd} 、 \mathrm{~Pb} 、 \mathrm{Zn}$, 其污染程度在 2009-2010 年前后达到峰值, 之后逐渐下降, 反映了与阳宗海流域 工业发展有关的污染物的排放以及 2008 年砷污染事件后采用的絮凝剂吸附沉淀除砷对沉积物重金属富集 的影响. 表层沉积物中 $\mathrm{Zn} 、 \mathrm{~Pb}$ 为“弱一中等”污染, $\mathrm{As}$ 为“中等一强”污染, $\mathrm{Cd}$ 为“弱一强”污染, 说明目前阳宗 海仍然受到人为源重金属输人的影响.

生态风险评价结果表明,历史上重金属污染较强的时段 (2002-2010 年) 沉积物中重金属达到“中等一 强”潜在生态危害, 其生态风险依次为 $\mathrm{Cd}>\mathrm{As} \gg \mathrm{Pb} \approx \mathrm{Cu}>\mathrm{Ni} \approx \mathrm{Co} \approx \mathrm{Zn} \approx \mathrm{Cr}$. 表层沉积物中 $\mathrm{Cr} 、 \mathrm{Co} 、 \mathrm{Ni} 、 \mathrm{Zn} 、 \mathrm{Cu}$ 和 $\mathrm{Pb}$ 属于 “较低”生态风险程度; 部分采样点 $\mathrm{Cd}$ 和 $\mathrm{As}$ 仍具有 “中等一强” 潜在生态风险, 主要分布在阳宗海 中东部湖区.

致谢: 罗文磊、林琪、宁栋梁等协助完成野外采样, 朱育新副研究员协助完成金属元素测定, 夏威岗高级工程 师负责完成沉积岩芯年代测定,在此深表感谢. 


\section{4 参考文献}

[ 1 ] Chen CW, Kao CM, Chen CF et al. Distribution and accumulation of heavy metals in the sediments of Kaohsiung Harbor, Taiwan. Chemosphere, 2007, 66: 1431-1440.

[ 2 ] Shi Zhifang, Jing Xia, Yang Suwen et al. The spatial and temporal variation characteristics and potential ecological risk assessment of heavy metal pollution in surface sediments of Chaohu, China. Journal of Agro-Environment Science, 2010,29 (5) : 948-954. [石志芳, 姜霞, 杨苏文等. 巢湖表层沉积物中重金属污染的时空变化特征及潜在生态风险评价. 农业环境科学学报, 2010, 29(5): 948-954.]

[ 3 ] Hiller E, Jurkovic L, Sutriepka M. Metals in the surface sediments of selected water reservoirs, Slovakia. Bulletin of Environmental Contamination and Toxicology, 2010, 84(5) : 635-640.

[ 4 ] Feng Jinglan, Hu Pengtuan, Liu Qun et al. Chemical speciation and risk assessment of heavy metals in the sediments from the mainstream of middle and lower reaches of Yellow River. Environmental Chemistry, 2015, 34(1) : 178-185. [冯精兰, 胡鹏抟, 刘群等. 黄河中下游干流沉积物中重金属的赋存形态及其生态风险. 环境化学, 2015, 34(1): 178-185.]

[ 5 ] Liu Enfeng, Shen Ji, Yang Liyuan et al. Assessment of heavy metal contamination in the sediments of Nansihu Lake Catchment, China. Environmental Monitoring and Assessment, 2010, 161: 217-227.

[ 6 ] Pan K, Wang WX. Trace metal contamination in estuarine and 1330 coastal environments in China. Science of the Total Environment, 2012, 421/422 : 3-16.

[ 7 ] Ma Xiuping, Jing Weixin, Wang Qian et al. Heavy metal pollution in the surface sediment of Dan River and its ecological risk assessment. Journal of Agro-Environment Science, 2010, 29(6) : 1180-1186. [马秀平, 井维金金, 王茜等. 丹河水系 表层沉积物重金属污染及生态风险评价. 农业环境科学学报, 2010, 29(6): 1180-1186.]

[ 8 ] Sun WP, Yu JJ, Xu XQ et al. Distribution and sources of heavy metals in the sediment of Xiangshan Bay. Acta Oceanologica Sinica, 2014, 33(4) : 101-107.

[ 9 ] Zhang Guanggui. Dongting Lake eco-environmental monitoring centre of Hunan Province, Yueyang. Environmental Monitoring in China , 2015, 31(6) : 58-64. [张光贵. 洞庭湖表层沉积物中重金属污染特征、来源与生态风险. 中国环境监 测, 2015, 31(6) : 58-64.]

[ 10] Tao Zhengkai, Bi Chunjuan, Chen Zhenlou et al. Characteristics and assessment of heavy metals pollution in the sediments of lake Dishui. Resources and Environment in the Yangtze Basin, 2014, 23(12): 1714-1720. [陶征楷, 毕春娟, 陈振楼 等. 滴水湖沉积物中重金属污染特征与评价. 长江流域资源与环境, 2014, 23(12)：1714-1720.]

[11] Zhang Yuxi, Sun Jichao, Xiang Xiaoping et al. A survey of heavy metals in sediments of Yangzonghai Lake in Yunnan Province: their source and distribution. Environmental Science \& Technology, 2010, 33(12): 171-175. [张玉玺, 孙继 朝, 向小平等. 云南阳宗海湖底沉积物重金属分布与来源. 环境科学与技术, 2010, 33(12): 171-175.]

[12] Rognerud S, Fjeld E. Trace element contamination of Norwegian Lake sediments. Ambio, 2001, 30(1) : 11-19.

[13] Li Zhiyuan, Yang Changliang, Li Shiyu et al. Speciation and distribution of arsenic and its stability assessment in Lake Yangzonghai sediments after arsenic pollution remediation. Environmental Science \& Technology, 2015, 38(2) : 41-47. [李智圆, 杨常亮, 李世玉等. 砷污染治理后阳宗海沉积物砷的分布与稳定性. 环境科学与技术, 2015, 38(2): 41-47.]

[14] Wang Zhenhua, He Bin, Pan Xuejun et al. Pollution levels, trends and risk assessment of As in Lake Yangzong, Yunnan. Science China Chemistry, 2011, 41(3) : 556-564. [王振华, 何滨, 潘学军等. 云南阳宗海砷污染水平、变化趋势及 风险评估. 中国科学: 化学, 2011, 41(3): 556-564.]

[15] Bi Jianpei, Liu Chen, Li Shaozuo. Variation of water quality of affected by arsenic Yangzonghai Lake pollution. Water Resources Protection, 2014, 30(1) : 84-89. [ 毕建培, 刘晨, 黎绍佐. 阳宗海砷污染水质变化过程分析. 水资源保护, $2014, \mathbf{3 0}(1): 84-89$.

[16] Qi Jianying, Xu Zhencheng, Li Xiangping et al. Study on source and speciation distribution characteristics of arsenic in Yangzonghai Lake waters. Journal of Anhui Agricultural Sciences, 2010, 38(20): 10789-10792. [齐剑英, 许振成, 李 祥平等. 阳宗海水体中砷的形态分布特征及来源研究. 安徽农业科学, 2010, 38(20): 10789-10792.]

[17] Zhang Yuxi, Sun Jichao, Xiang Xiaoping et al. Evaluation of ecological risk of heavy metals in surface sediments from Yangzonghai Lake. Water Resources Protection, 2012, 28(5): 19-24. [张玉玺, 孙继朝, 向小平等. 阳宗海表层沉积物中 
的重金属生态风险评估. 水资源保护, 2012, 28(5): 19-24.]

[18] N'guessan YM, Probst JL, Bur T et al. Trace elements in stream bed sediments from agricultural catchments (Gascogne region, S-W France): Where do they come from? Science of the Total Environment, 2009, 407: 2939-2952.

[19] Yuan Linna, Yang Changliang, Li Xiaoming et al. Effect of daily thermal stratification on dissolved oxygen, pH, total phosphorus concentration, phytoplankton and algae density of a deep plateau lake: A case study of Lake Yangzonghai, Yunnan Province. J Lake Sci, 2014, 26(1) : 161-168. DOI: 10.18307/2014.0120. [袁琳娜, 杨常亮, 李晓铭等. 高原 深水湖泊水温日成层对溶解氧、酸碱度、总磷浓度和藻类密度的影响: 以云南阳宗海为例. 湖泊科学, 2014, 26 (1) : 161-168. ]

[20] Appleby PG. Chronostratigraphic techniques in recent sediments. In: Last WM, Smol JP eds. Tracking environmental change using lake sediments. Dordrecht: Springer Netherlands, 2001: 171-203.

[21] Li Na, Wang Zhenzhen. Review in ecological risk assessment methods for heavy metal polluted sediments. Inner Mongolia Petrochemical Industry, 2012, 23: 11-12. [李娜, 王珍珍. 沉积物重金属污染生态风险评价方法浅析. 内蒙古石油 化工, 2012, 23: 11-12.]

[22] Chen Ming, Cai Qingyun, Xu Hui et al. Research progress of risk assessment of heavy metals pollution in water body sediments. Ecology and Environmental Sciences, 2015, 24(6): 1069-1074. [ 陈明, 蔡青云, 徐慧等. 水体沉积物重金属污 染风险评价研究进展. 生态环境学报, 2015, 24(6): 1069-1074.]

[23] Wu YH, Hou XH, Cheng XY et al. Combining geochemical and statistical methods to distinguish anthropogenic source of metals in lacustrine sediment: a case study in Dongjiu Lake Taihu Lake catchment. China Environmental Geology, 2007, 52( 8) : 1467-1474.

[24] Du Chenchang, Liu Enfeng, Yang Xiangdong et al. Characteristics of enrichment and evaluation of anthropogenic pollution of heavy metals in the sediments of Lake Chaohu. J Lake Sci, 2012, 24(1) : 59-66. DOI: 10.18307/2012.0108. [杜臣 昌, 刘恩峰，羊向东等. 巢湖沉积物重金属富集特征与人为污染评价. 湖泊科学, 2012, 24(1) : 59-66.]

[25] Liu EF, Shen J, Yang XD et al. Spatial distribution and human contamination quantification of trace metals and phosphorus in the sediments of Chaohu Lake, a eutrophic shallow lake, China. Environmental Monitoring and Assessment, 2012, 184(4) : 2105-2118.

[26] Reimann C, de Caritat P. Distinguishing between natural and anthropogenic sources for elements in the environment: regional geochemical surveys versus enrichment factors. Science of the Total Environment, 2005 , 337: 91-107.

[27] Zhang EL, Liu EF, Shen J et al. One century sedimentary record of Lead and Zinc pollution in Yangzong Lake, a highland lake in southwestern China. Journal of Environmental Sciences, 2012, 24(7) : 1189-1196.

[28] Yan Ting, Liu Enfeng, Zhang Enlou et al. The spatio-temporal variations of heavy metals in the sediment of Lake Fuxian and the contamination assessment. J Lake Sci, 2016, 28(1) : 50-58. DOI: 10.18307/2016.0106. [燕婷, 刘恩峰, 张恩 楼等. 抚仙湖沉积物重金属时空变化与人为污染评价. 湖泊科学, 2016,28(1): 50-58.]

[29] Håkanson L. An ecological risk index for aquatic pollution control: a sedimentological approach. Water Research, 1980,14 (8) : 975-1001.

[30 ] Fang Ming, Wu Youjun, Liu Hong et al. Distribution, sources and ecological risk assessment of heavy metals in sediments of the Yangtze River estuary. Acta Scientiae Circumstantiae, 2013, 33(2) : 563-569. [方明, 吴友军, 刘红等. 长江口沉 积物重金属的分布、来源及潜在生态风险评价. 环境科学学报, 2013, 33(2)：563-569.]

[31] Wu Wenxing, Li Kaiming, Wang Guang et al. Evaluation of heavy metal pollution in river sediment: a comparative case study in Tanjiang River. Environmental Science \& Technology, 2012, 35(9) : 143-149. [ 吴文星, 李开明, 汪光等. 沉积 物重金属污染评价方法比较——以潭江为例. 环境科学与技术, 2012, 35(9): 143-149.]

[32] Wu Bin, Song Jinming, Li Xuegang et al. Consensus-based sediment quality guidelines( CBSQGs) and its application in coastal sediment quality assessment. Environmental Chemistry, 2011, 30(11)：1949-1956. [ 吴斌, 宋金明, 李学刚. 一 致性沉积物质量基准 (CBSQGs) 及其在近海沉积物环境质量评价中的应用. 环境化学, 2011, 30(11): 1949-1956. ]

[33] Liu Xin, Jiang Yu, Gao Junfeng et al. Pollution characteristics of heavy metals and the risk assessment for the surface sediments from Lake Chaohu and its main tributary rivers. J Lake Sci, 2016, 28(3) : 502-512. DOI : 10.18307/2016.0305. [刘新, 蒋豫, 高俊峰等. 巢湖湖区及主要出入湖河流表层沉积物重金属污染特征及风险评价. 湖泊科学, 2016, 28(3): 502-512.] 
[34] MacDonald, Ingersoll CG, Berger TA. Development and evaluation of consensus-based sediment quality guidelines for freshwater ecosystems. Archives of Environmental Contamination and Toxicology, 2000, 39(1) : 20-31.

[35] Liu Enfeng, Xue Bin, Yang Xiangdong et al. Dating method of modern sediments based on the distribution of ${ }^{210} \mathrm{~Pb}$ and ${ }^{137}$ Cs. Marine Geology \& Quaternary Geology, 2009, 29(6): 84-89. [刘恩峰, 薛滨, 羊向东等. 基于 ${ }^{210} \mathrm{~Pb}$ 与 ${ }^{137} \mathrm{Cs}$ 分布 的近代沉积物定年方法. 海洋地质与第四纪地质, 2009, 29(6) : 84-89.]

[36] Liu Yilan, Zhang Enlou, Liu Enfeng et al. The TOC and BC records in sediment of Yangzong Lake under the influence of human activities during the past century. J Lake Sci, 2017, 29(4) : 1018-1028. DOI: 10.18307/2017.0426. [刘一兰, 张恩楼, 刘恩峰等. 人类活动影响下的阳宗海近百年有机碳与黑炭湖泊沉积记录. 湖泊科学, 2017, 29(4): 1018-1028.]

[37] Sutherland RA. Bed sediment-associated trace metals in an urban stream, Oahu, Hawaii. Environmental Geology, 2000, 39: 611-627.

[38 Ma Yingjun, Wan Guojiang, Liu Congqiang et al. The seasonal migration of lugu lake redox boundary layer and its influence on water quality. Journal of Environmental Science, 2000, 20(1): 27-32. [马英军, 万国江, 刘丛强等. 泸沽湖氧 化还原边界层的季节性迁移及其对水质的影响. 环境科学学报, 2000, 20(1): 27-32.]

[39] Wersin P, Höhener P, Giovanoli R et al. Early diagenesis influences on iron transformations in a freshwater lake sediment. Chemical Geology, 1991, 90: 233-252.

[40] Wan Guojiang, Chen Zhenlou, Wan Xi et al. Research of Fe-Mn cycle on lake sediment and water interface. Geology-Geochemistry, 1996, (2) : 5-8. [万国江, 陈振楼, 万曦等. 湖泊沉积物-水界面 Fe-Mn 循环研究新进展. 地质地球化 学, 1996, (2): 5-8.]

[41] Liu Weihong, Yang Changliang, Fu Qiang et al. Analysis on eco-environmental water demand and environmental functions of Yangzonghai Lake. Environmental Science and Management, 2012, 37(2): 121-126. [刘卫红, 杨常亮, 傅强等. 阳 宗海生态环境蓄水量及环境功能解析. 环境科学与管理, 2012, 37(2) : 121-126.]

[42] Wang Shixiong, Jiang Fengzhi, Chen Jing. Removal of arsenic in Yangzonghai Lake by ferric salt coagulation method and the stability of its precipitate in sediment. Geoscience, 2015, 29(2) : 361-369. [王世雄, 蒋峰芝, 陈景. 铁盐絮凝法对 阳宗海湖泊水体的除砷效果及底泥的稳定性考察. 现代地质, 2015, 29(2) : 361-369.]

[43] Liu Yong, Zhu Yuanrong, Wu Fengchang et al. Pollution characteristics and ecological risk assessment of heavy metals in sediments of Dianchi Lake. Ecology and Environmental Sciences, 2014, 23(7): 1181-1186. [刘勇, 朱元荣, 吴丰昌等. 滇池沉积物中重金属污染特征及其生态风险评估. 生态环境学报, 2014, 23(7): 1181-1186.]

[44] Yu Shen, Li Hongbo. Perspectives on the release of heavy metals via sediment resuspension. Ecology and Environmental Sciences, 2010, 19(7): 1724-1731. [俞慎, 历红波. 沉积物再悬浮-重金属释放机制研究进展. 生态环境学报, $2010,19(7): 1724-1731$.]

[45] Liu EF, Zhang EL, Li K et al. Historical reconstruction of atmospheric lead pollution in central Yunnan province, southwest China: An analysis based on lacustrine sedimentary records. Environmental Science and Pollution Research, 2013, 20: $8739-8750$. 